\title{
Manuscript
}

\section{Visible Light-Induced Sulphide Anion-Catalysed Decarboxylative Alkylations in Batch and Continuous Flow}

\author{
Meng-Ting Liu, ${ }^{2, \dagger}$ De-Guang Liu, ${ }^{1, \uparrow}$ Zhi-Wei Qin², Guang-Zu Wang ${ }^{1,2}$
}

${ }^{1}$ Department of Chemistry, University of Science and Technology of China, Hefei 230026, China

${ }^{2}$ Institute of Advanced Technology, University of Science and Technology of China, Hefei 230031, China

These authors contributed equally: Meng-Ting Liu and De-Guang Liu.

Correspondence and requests for materials should be addressed to G.-Z.W. (email: wgz@mail.ustc.edu.cn).

\begin{abstract}
We demonstrated herein a versatile protocol for visible-light-induced sulphide anion-catalysed decarboxylative cross-couplings. An array of primary, secondary, tertiary and amino acid-derived redox-active esters (RAEs) were all amenable substrates to undergo radical decarboxylation to be coupled with a diverse range of nucleophiles, creating challenging $\mathrm{C}\left(\mathrm{sp}^{3}\right)-\mathrm{C}\left(\mathrm{sp}^{3}\right)$ and $\mathrm{C}\left(\mathrm{sp}^{3}\right)-\mathrm{C}\left(\mathrm{sp}^{2}\right)$ bonds with high efficiency. We note that Katritzky's salt and Togni's reagent were also suitable substrates, affording deaminative alkylation and trifluoromethylation products in high yields. Density functional theory calculations and mechanism experiments indicate that a charge-transfer complex was formed between sulphide anions and RAEs in the amide solvent. Additionally, a one-pot two-step telescoped procedure and continuous-flow process further increase the synthetic utility of this catalytic system.
\end{abstract}

\section{Introduction}

Sulphur atoms are found in a wide variety of natural products, drugs, organic materials, agrochemicals, and small molecules of medicinal interest ${ }^{[1-3]}$. The large size (1.02 $\AA$ ) and low electronegativity (2.4) of the sulphur atom make the outer electron shell more prone to accept and 
donate electrons, resulting in its multiplicity of valence (Figure $1 \mathrm{~A})^{[4]}$. Almost every atom (except inert elements) can bond with sulphur atoms, and its valence state can vary from -2 to $6^{[5]}$. The excellent electron-transfer ability and radical properties of sulphur-containing backbones make them ideal candidates for catalysis $^{[6]}$, particularly in the photoredox pathway ${ }^{[7]}$. To date, numerous sulphur-containing photosensitizers have been synthesized and employed in visible-light-induced transformations, such as disodium benzophenondisulphonate (BPSS) ${ }^{[8]}$, thiazine dyes ${ }^{[9]}$, thiophene derivatives $^{[10]}$ and $\mathrm{N}$-phenylphenothiazine $(\mathrm{PTH})^{[1]}$. Although considerable progress has been made in this area, the high cost and complex synthesis of the catalysts have impeded their application in large-scale industrial processes. Consequently, developing a new photocatalyst based on this inexpensive and abundant element is highly desirable.

(A) Sulfur and Sulfur-containing photocatalysts
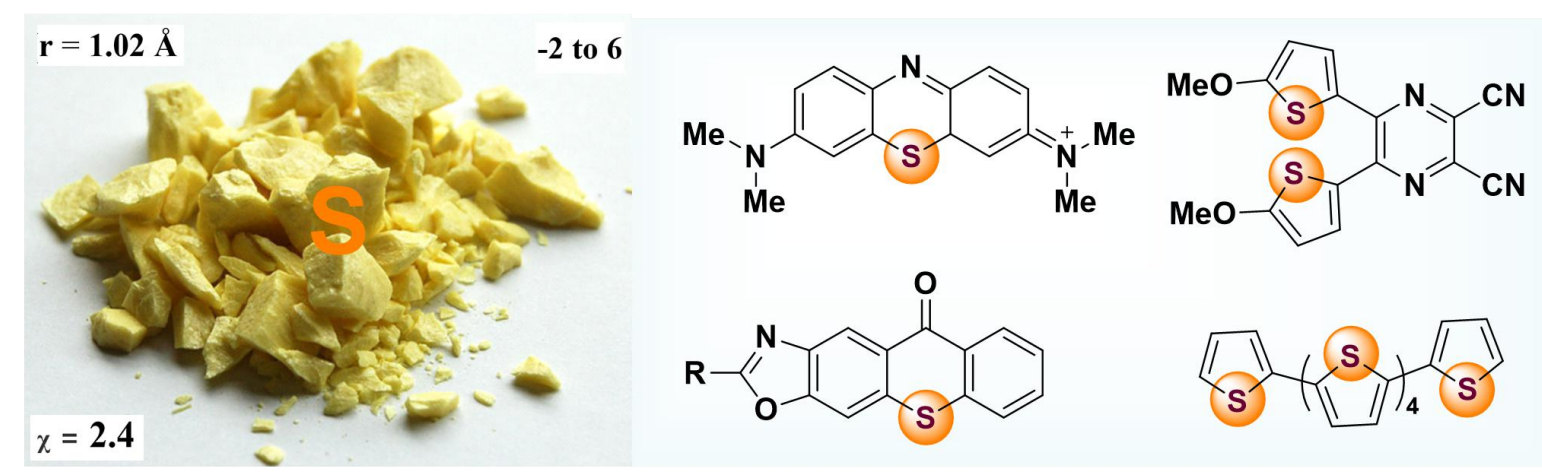

(B) Charge-transfer complex (CTC) enabled photoredox process via anion- $\pi$ bonding

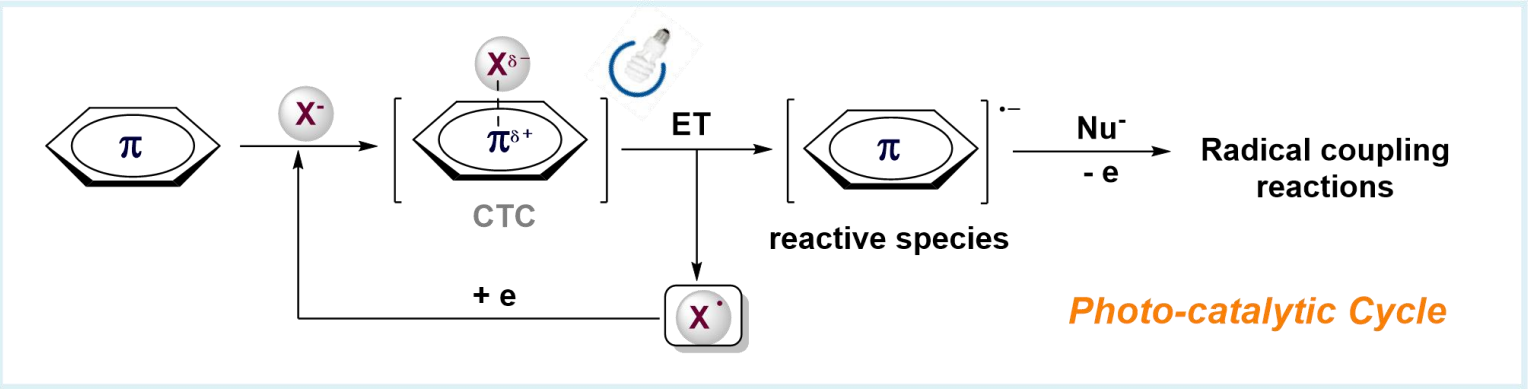

(C) Visible-light-induced sulfide anions-catalyzed decarboxylative alkylations (This work)

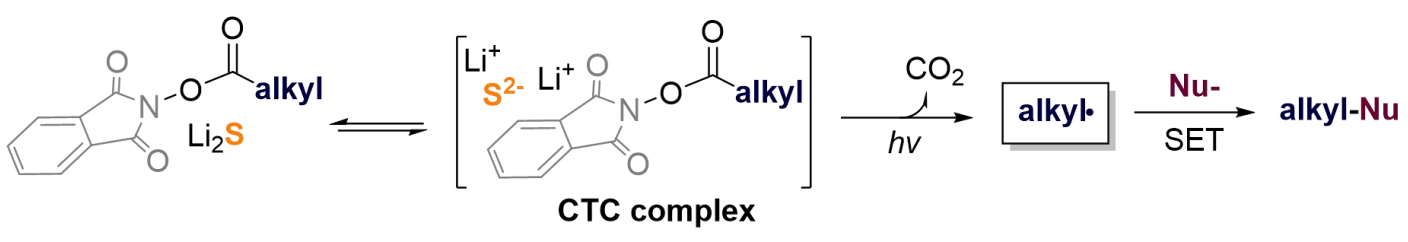

Figure 1 Sulphide anion-catalysed decarboxylative alkylation via photoactivation of the anion- $\pi$ interaction-assembled charge transfer complex (CTC)

Noncovalent interactions are of fundamental importance in many areas of modern chemistry and have been vital in the development of fast chemical dynamics ${ }^{[12-13]}$. Anion- $\pi$ bondings, which was commonly defined as an attraction of anions to the electron-deficient (olefinic or aromatic) 
$\pi$-systems, have recently emerged as one of the most interesting noncovalent interactions ${ }^{[14-16]}$. The anion- $\pi$ assembled charge-transfer complex (CTC) was found to be activated via photoactivation to undergo intermolecular electron transfer (IET), thus affording reactive radical ion pairs and anion radical intermediates (Figure $1 \mathrm{~B})^{[17-18]}$. In 2019, Shang and $\mathrm{Fu}$ reported the first photocatalysed decarboxylative alkylations enabled by $\mathrm{PPh}_{3}$ and $\mathrm{NaI}^{[19]}$. It is worthy noted that the CTC was formed with a cheap iodized salt, a sample phosphorus ligand, and an electron-accepting substrate, avoiding the use of the traditional metal- or dye complex-based photosensitizer ${ }^{[20-22]}$. Inspired by this, we questioned whether sulphide anions with better electron-transfer ability and radical properties could also exhibit the similar catalytic reactivity (Figure $1 C$ ).

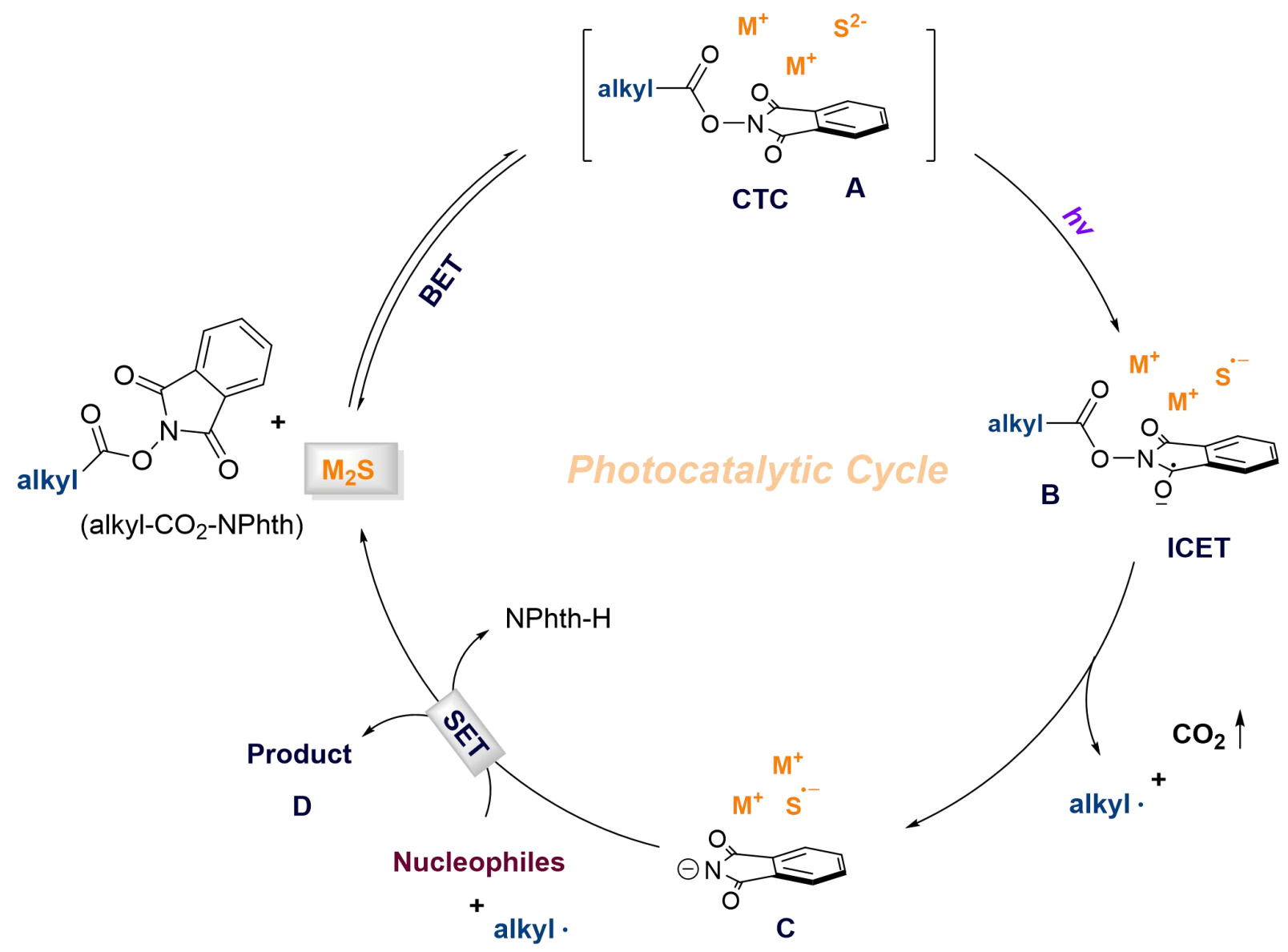

Figure 2 | Proposed photocatalytic cycle

The proposed mechanism for sulphide anion-catalysed decarboxylative alkylation is illustrated in Figure 2. Initially, charge transfer complex $\mathbf{A}$ is dynamically formed with redox-active esters (RAEs) and sulphide anions through anion- $\pi$ interactions in the solvent cage. Then, intermolecular electron transfer (ICET) from sulphide anions to RAEs is induced through photoactivation of CTC, thus affording radical ion pair intermediate $\mathbf{B}$. (Note: this step is critical, because the photoexcitation state B can either return to $\mathbf{A}$ through the back electron transfer pathway ${ }^{[23]}$ or collapse to form the free sulphide radicals and alkyl radicals). Afterwards, the fragmentation of $\mathbf{B}$ occurs via decarboxylation to generate alkyl radicals and sulphide radical intermediate $\mathbf{C}$. Finally, the alkyl radical attacks the 
nucleophiles, followed by single electron transfer and deprotonation by $\mathrm{Nphth}^{-}$to deliver alkylation product $\mathbf{D}$.

\section{Results and Discussion}

Substrates scope. The optimized reaction conditions for the decarboxylative alkylation of isocyanide are demonstrated in Figure 3. Irradiation the reaction mixture of $\mathrm{N}$-(tert-butylacyloxy)phthalimide (1, 0.3 mmol), 2-isocyano-1,1'-biphenyl (2, $0.2 \mathrm{mmol})$ and $\mathrm{Li}_{2} \mathrm{~S}$ (20 mol \%) in DMA (2.0 mL) solvent by purple LEDs $(427 \mathrm{~nm})$ for $12 \mathrm{~h}$, delivering the desired alkylation product (3) in 96\% yield. The key parameters that affect the reacion are summarized in Figure $3 \mathrm{~A}$. In addition to $\mathrm{Li}_{2} \mathrm{~S}, \mathrm{Na}_{2} \mathrm{~S}$ and $\mathrm{K}_{2} \mathrm{~S}$ are also suitable catalysts to deliver 3 in good yields. However, other sulphide salts, such as FeS, ZnS, SnS and CdS, were less effective. Organic sulphides PhSNa exhibited good catalytic activity in this reaction system. Control experiments revealed that cayalyst and light irradiation are both crucial. This catalytic system is highly sensitive to oxygen but is not sensitive to water. Moreover, the concentration effect is also significant to this reaction, and a relatively high concentration is necessary. We also investigated the dependence of the reaction on the light wavelength, and it was found that the purple LEDs $(427 \mathrm{~nm})$ and blue LEDs (440 $\mathrm{nm}, 456 \mathrm{~nm})$ exhibited better performance than the other light sources, including ultraviolet radiation (390 $\mathrm{nm}$ ), green LEDs $(520 \mathrm{~nm})$ and red LEDs $(730 \mathrm{~nm})$. It is noteworthy that alkyl halides (iodide, bromide and chloride) were all ineffective, which is attributed to their inability to form CTC complexes. For solvent optimization, we found that amide solvents (DMA, DMF, NMP) and dimethyl sulphoxide were all favourable solvents for this photoinduced sulphide-catalysed reaction.

To provide a further understanding of the charge transfer complex-enabled photoredox system, the UV-Vis absorption spectrum ${ }^{[2]}$ of the reaction mixture was then measured with the same concentration used in the standard reaction condition (Figure $2 \mathrm{~B}$ ). No obvious absorption in the visible region was observed for the $\mathrm{Li}_{2} \mathrm{~S}$ solution, and the RAE (1) showed an absorption onset at approximately $390 \mathrm{~nm}^{[25]}$. A strong bathochromic shift, tailing into the wavelength range of purple LEDs and even blue LEDs occurred when $\mathrm{Li}_{2} \mathrm{~S}$ was mixed with 1 . It is important to note that the solution developed an umber colour change from colourless when $\mathbf{1}$ was mixed with $\mathrm{Li}_{2} \mathrm{~S}$ (aquamarine blue) in DMA. This phenomenon is in accordance with the bathochromic shift of UV-Vis absorption that is diagnostic of charge transfer complex formation in the reaction system. Finally, a light "on/off” experiment was conducted to indicate that uninterrupted irradiation is necessary for this transformation (Figure $\left.{ }_{3} \mathrm{C}\right)^{[26]}$. 
(A)

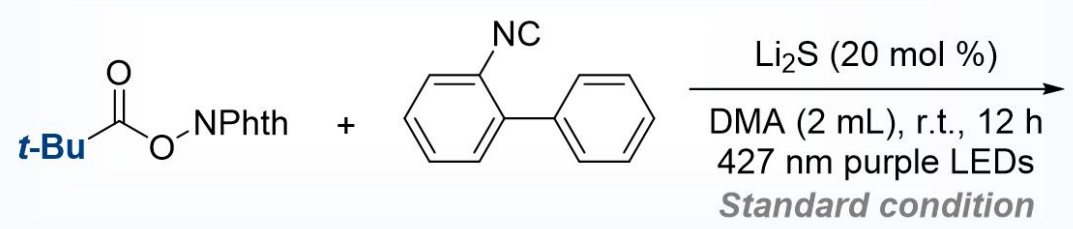<smiles>CC(C)(C)c1nc2ccccc2c2ccccc12</smiles>

$1,0.3 \mathrm{mmol}$

2, $0.2 \mathrm{mmol}$

$3,96 \%\left(92 \%{ }^{a}\right)$

\section{Different alkali halides in lieu of $L_{i} S$}

$\begin{array}{cccccccc}\mathrm{Li}_{2} \mathrm{~S} & \mathrm{Na}_{2} \mathrm{~S} & \mathrm{~K}_{2} \mathrm{~S} & \mathrm{FeS} & \mathrm{ZnS} & \mathrm{SnS} & \mathrm{CdS} & \mathrm{PhSNa} \\ 96 \% & 90 \% & 88 \% & 41 \% & 24 \% & 12 \% & 62 \% & 72 \%\end{array}$

\section{Control experiments}

\section{Effect of concentration}

$\begin{array}{ccccccc}\text { w/o Li } 2 \mathrm{~S} & \text { w/o purple LEDs } & \text { under air } & 2 \text { equiv } \mathrm{H}_{2} \mathrm{O} & \boldsymbol{c}=0.2 \mathrm{M} & 0.1 \mathrm{M} & 0.05 \mathrm{M} \\ 12 \% & <1 \% & <1 \% & 95 \% & 91 \% & 96 \% & 86 \%\end{array}$

4. Wavelength effect

\section{Other electrophiles}

$\begin{array}{ccccccccc}390 \mathrm{~nm} & 427 \mathrm{~nm} & 440 \mathrm{~nm} & 456 \mathrm{~nm} & 520 \mathrm{~nm} & 730 \mathrm{~nm} & \mathrm{t}-\mathrm{Bu}-\mathrm{l} & \mathrm{t}-\mathrm{Bu}-\mathrm{Br} & \mathrm{t}-\mathrm{Bu}-\mathrm{Cl} \\ 90 \% & 96 \% & 95 \% & 94 \% & 57 \% & 32 \% & 0 \% & 0 \% & 0 \%\end{array}$

\section{Solvation effect}

DMA DMF DMSO NMP EtOAc Toluene THF $\mathrm{CH}_{3} \mathrm{CN} \mathrm{MeOH}$

$96 \% \quad 95 \% \quad 94 \% \quad 88 \% \quad 13 \% \quad<1 \% \quad 44 \% \quad 3 \% \quad 2 \%$

(B)

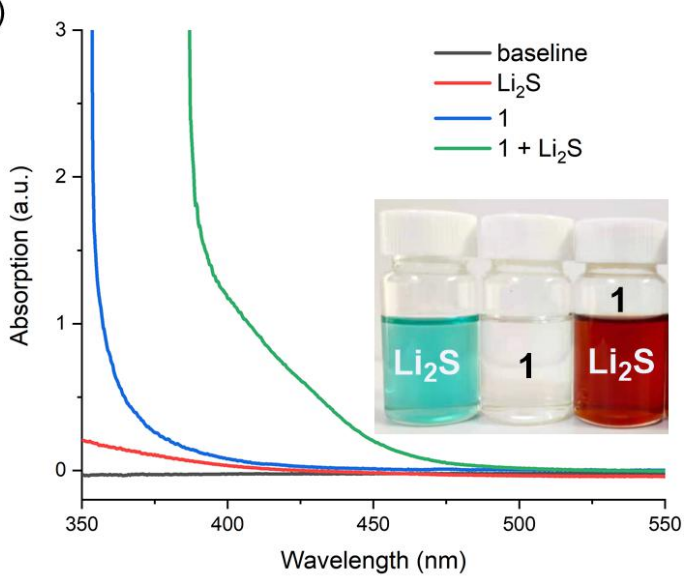

(C)

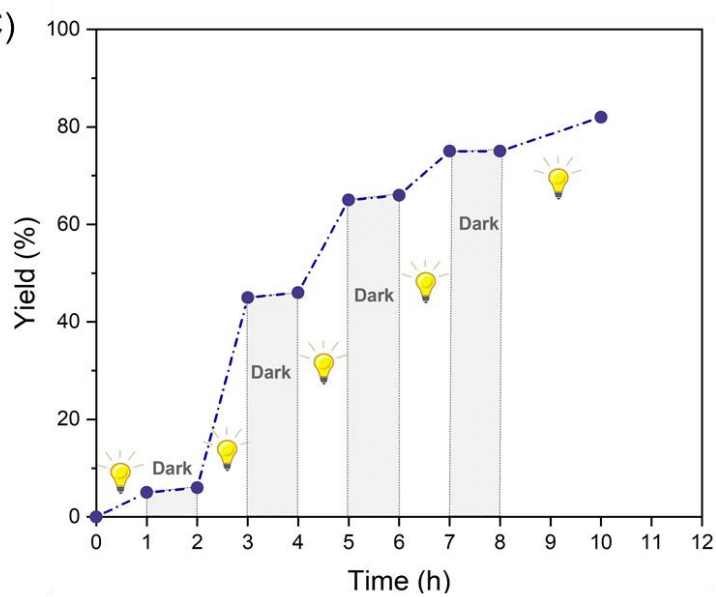

Figure 3 | (A) Parameters affecting the sulphide anion-catalysed decarboxylative alkylations. (B) UV-Vis absorption spectrum of reactant mixtures and Electronic photos of different components in DMA solution. (C) On/off experiment. Yield determined by gas chromatography (GC) using diphenylmethane as an internal standard. ${ }^{a}$ Isolated yield.

Substrates scope. Encouraged by these results, we set out to explore the scope of this transformation. Satisfyingly, this catalytic system featured broad substrate scope and good functional group compatibility under the optimized reaction conditions (Table 1). Isocyanides substituted with electron-neutral $(3,4)$ and electron-donating (5) and electron-groups $(6)$ all gave good to excellent yields. 
alkyl ${ }_{O_{-} N P h t h+}^{O}$

$150 \mathrm{~mol} \%$ - $200 \mathrm{~mol} \%$

$0.2 \mathrm{mmol}$
$\underset{\mathrm{Li}_{2} \mathrm{~S}(20 \mathrm{~mol} \%)}{\operatorname{DMA}(2 \mathrm{~mL}), \text { r.t., } 12 \mathrm{~h}}$

$427 \mathrm{~nm}$ purple LEDs

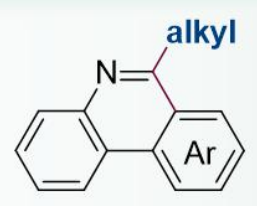

3 - 29

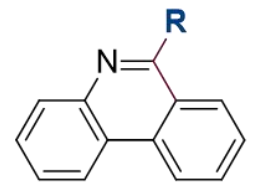

3, $\mathrm{R}=-\mathrm{t}-\mathrm{Bu}, 92 \%$

4, $R=-C y, 71 \%$

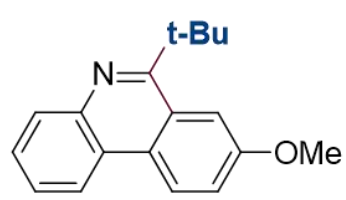

5, $85 \%$

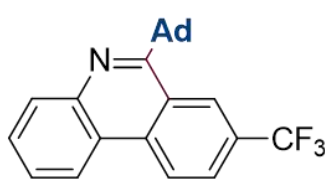

6, $71 \%$

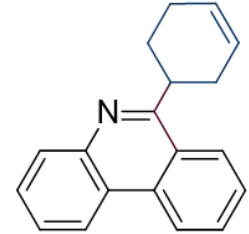

$7,82 \%$
Ts<smiles>c1ccc2c(c1)nc(C1CNC1)c1ccccc12</smiles>

$8,72 \%$<smiles>CC1CC=CCCC1Nc1nc2ccccc2c2ccccc12</smiles>

$12,55 \%^{b}$<smiles>[I-]N1CCCC(c2nc3ccccc3c3ccccc23)C1</smiles>

9, $75 \%$<smiles>O=C(c1ccc(Cl)nc1)N1CCC(c2nc3ccccc3c3ccccc23)CC1</smiles>

$10,61 \%$<smiles>Cc1ccc(C)c(OCC(C)(C)c2nc3ccccc3c3ccccc23)c1</smiles>

$11,97 \%$

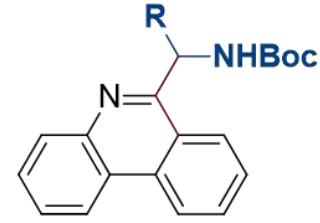

16, $\mathrm{R}=-\mathrm{Me}, 65 \%$

$17, R=-B n, 78 \%$<smiles>COC(=O)CCC(NC(C(=O)OC)C(=O)OC)c1nc2ccccc2c2ccccc12</smiles>

$22,64 \%$

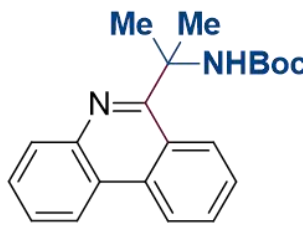

26, $84 \%$<smiles>CC(C)[C@H]1CCCCC1OC(=O)CCc1nc2ccccc2c2ccccc12</smiles>

$13,51 \%^{b}$, d.r. $=1: 1$<smiles>c1ccc2c(c1)nc(C1CCCO1)c1ccccc12</smiles>

$14,76 \%$<smiles>CC(Oc1cccc(Cl)c1)c1nc2ccccc2c2ccccc12</smiles>

$15,61 \%$

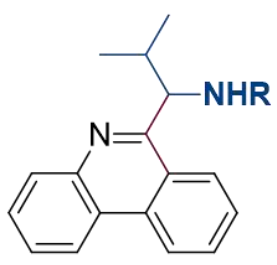

18, $R=-C b z, 63 \%$

$19, R=-A c, 75 \%$<smiles>CC(C)(C)OCCNCC(N)c1nc2ccccc2c2ccccc12</smiles>

$23,52 \%$

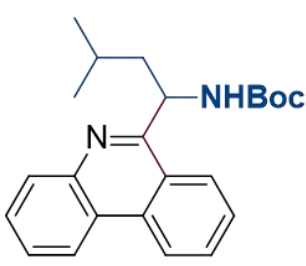

20, $76 \%$<smiles>CC(C)(C)OC(=O)N1CCCC1c1nc2ccccc2c2ccccc12</smiles>

$24,98 \%$<smiles>CCCCOC(=O)C(CCc1nc2ccccc2c2ccccc12)NC(=O)OCC</smiles>

$21,54 \%^{b}$

$25,86 \%$

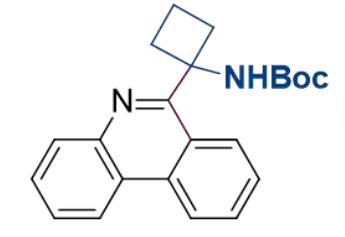

$27,66 \%$

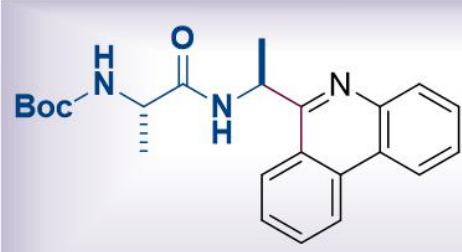

$28,76 \%$, d.r. $=1: 1$

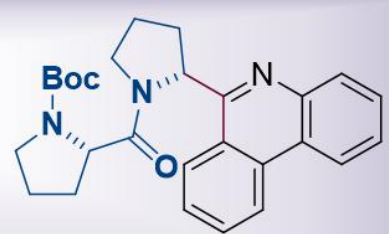

$29,74 \%$, d.r. $=1.2: 1$

Table 1 | Sulphide anion-catalysed decarboxylative alkylation of isocyanides. ${ }^{a}$ Reaction conditions: Isocyanides (o.2 mmol), RAEs (o.3 mmol) in DMA ( $2 \mathrm{~mL})$, irradiation with purple LEDs $(427 \mathrm{~nm}, 40 \mathrm{~W})$ at room temperature for $12 \mathrm{~h}$ under argon atmosphere. ${ }^{b} \mathrm{RAEs}(\mathrm{o} .4 \mathrm{mmol})$. 
A variety of primary, secondary and even tertiary RAEs (3 - 29) were all amenable substrates to deliver the corresponding decarboxylative alkylation products in moderate to excellent yields $(51 \%$ 98\%). Moreover, pharmaceutically relevant aliphatic structures, such as substituted piperidine (9, 10), and even more strained four-membered rings (8), are also effective in this reaction manifold. Excitingly, RAEs derived from natural product, such as Erucic acid (12), and drug molecules, like gemfibrozil (11) and monomethyl succinate (13), were all tolerated. It is important to mention that $\alpha$-alkoxy acid (14, 15), amino acid (16 - 27) and even peptide $(\mathbf{2 8}, \mathbf{2 9})$-derived redox esters were all amenable substrates for obtaining alkylation products in good to excellent yields ${ }^{[27]}$.

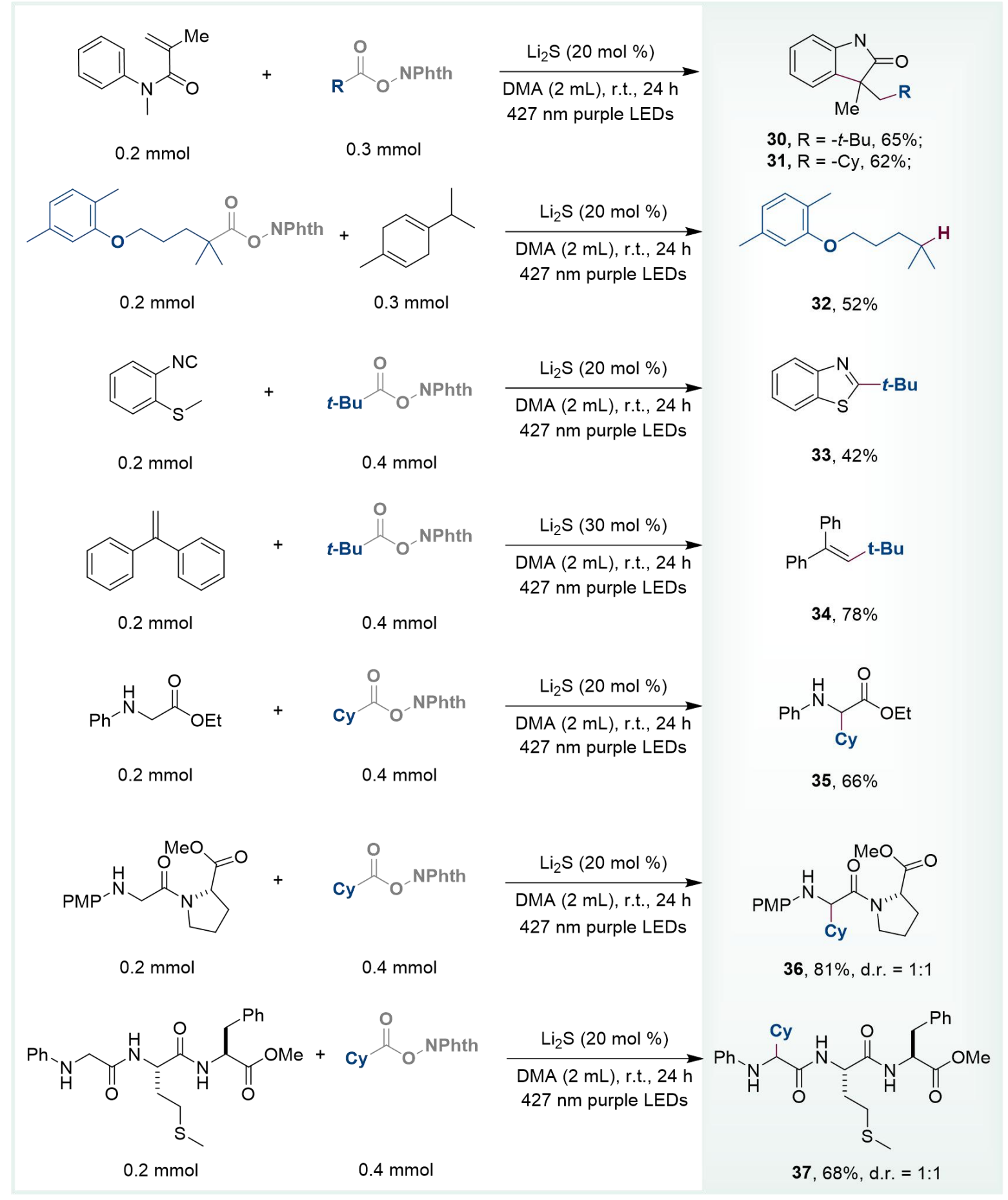

Scheme 1 | Photoinduced sulphide anion-catalysed decarboxylative alkylation of RAEs with other nucleophiles via charge-transfer complex 
To further expand the scope of the photoinduced sulphide anion catalytic system, we examined decarboxylative alkylation of RAEs with other nucleophilic reagents (Scheme 1), including $N$-alkyl- $N$-phenylalkacrylamides ${ }^{[28]}$ (30, 31), $\gamma$-terpinene ${ }^{[29]}$ (32), (2-isocyanophenyl)(methyl)sulphane $e^{[30]}$ (33), ethene-1,1-diyldibenzene ${ }^{[31]}$ (34) and arylglycine derivatives and peptides ${ }^{[32]}(35$ - 37). It was found that all of these compounds could undergo photoinduced decarboxylation to yield alkylation products in moderate to good yields. In addition to RAEs, Katritzky's salt ${ }^{[33]}$ and Togni's reagent ${ }^{[34]}$ were also demonstrated to be suitable substrates, affording deaminative alkylation and trifluoromethylation products with high efficiency (Scheme 2). Moreover, we were delighted to find that aryl carboxylic acid-derived redox-active esters ${ }^{[35]}$ were also amenable substrates, delivering the intramolecular decarboxylative arylation product (39) in high yield.

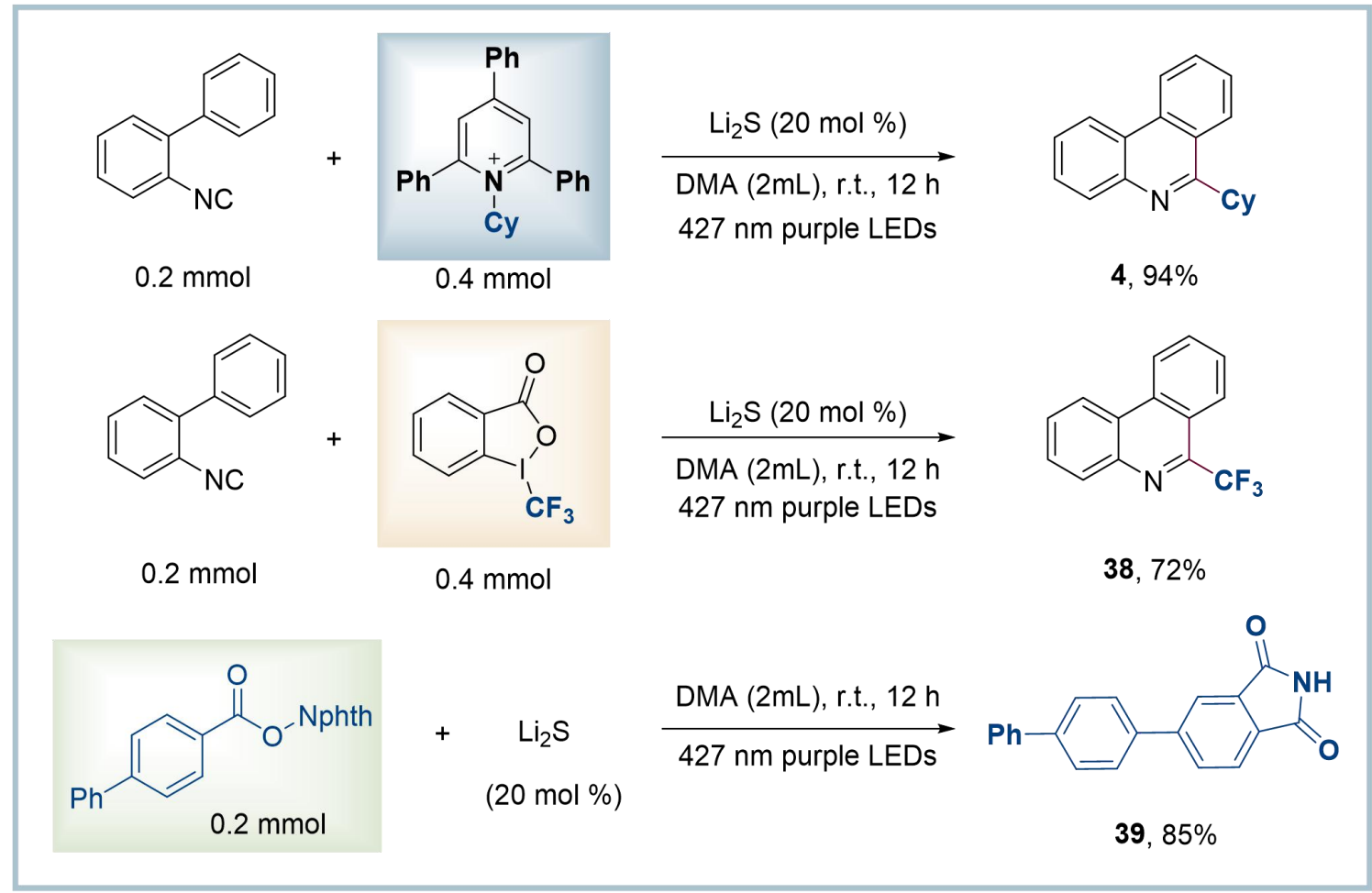

Scheme 2 | CTC-enabled sulphide anion-catalysed alkylations with other electrophiles

To increase the synthetic utility of this catalytic system, we implemented a two-step telescoped sequence to form RAE 1 in situ and use it without further purification (Scheme 3). A comparable yield was obtained under the optimum conditions, thus adding a synthetically valuable dimension to the CTC catalytic platform. Moreover, we also applied this sample catalytic system to the continuous-flow condition ${ }^{[36-37]}$. The same results can be achieved in just 10 minutes compared with the standard conditions (12 h), further enhancing the synthetic application value of this approach.

Mechanism studies: Finally, density functional theory (DFT) calculations were conducted to 
further elucidate the reaction pathway (Scheme 4$)^{[38]}$. Initially, the charge-transfer complex (CTC) was spontaneously assembled with $\mathrm{Li}_{2} \mathrm{~S}$ and RAEs (1) in $N, N$-dimethyl acetamide solvent. The ground state complex $\left(\mathbf{S}^{\mathbf{0}}\right)$ was activated with purple LEDs $(427 \mathrm{~nm})$ to generate a singlet excited $\mathbf{S}^{\mathbf{1}}$ state. Then, the $\mathbf{S}^{\mathbf{1}}$ state decays via intersystem crossing (ISC) to the corresponding triplet excited state $\mathbf{T}^{\mathbf{1}}$ and transforms to the optimized triplet excited state $\left(\mathbf{T}_{2}\right)$ via relaxation process. Subsequently, photo-induced intermolecular single electron transfer $\left(\right.$ ISET) proceeded $\left(\mathbf{T}_{2} \rightarrow\right.$ TS1', $\Delta G^{\neq}=8.0$ $\mathrm{kcal} / \mathrm{mol}$ ), leading to decarboxylation and generating tert-butyl free radicals (IN2) and sulphide radical cations. It is important to note that an enormous activation energy barrier must be overcome $\left(\mathbf{S}^{\mathbf{o}} \rightarrow \mathbf{T S 1} \mathbf{1}^{\prime}, \Delta G^{\neq}=35.1 \mathrm{kcal} / \mathrm{mol}\right)$ in the absence of visible light, proving further proof for the necessity of irradiation.

(a) One-Pot Telescoped

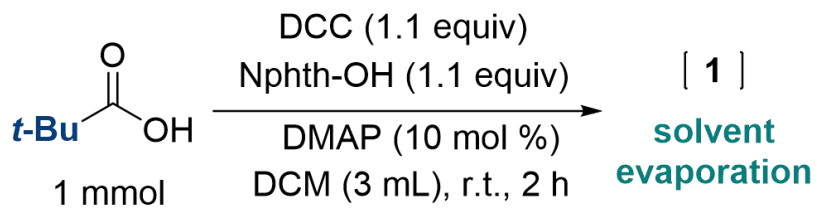

(b) In Continuous-Flow

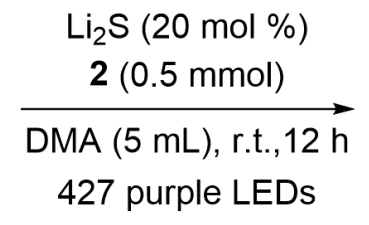

427 purple LEDs

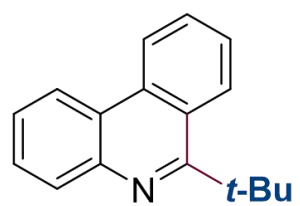

$3,86 \%$
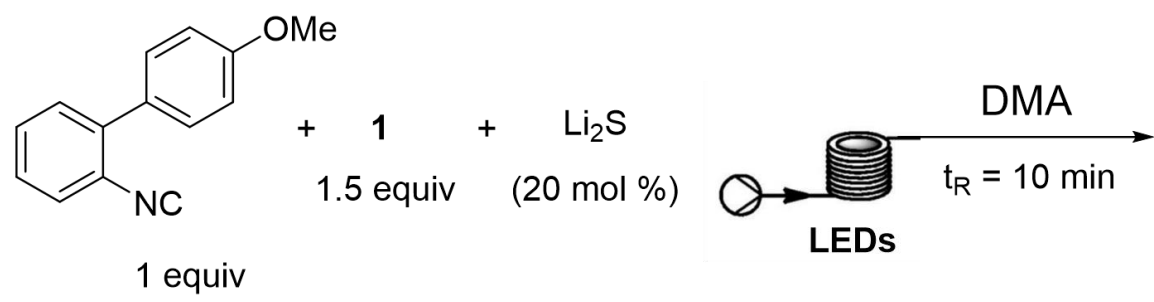<smiles></smiles>

$5,88 \%$

Scheme 3 | Decarboxylative alkylation with a one-pot two-step Telescoped procedure and in continuous-flow conditions

In the following step, the obtained alkyl radical IN2 will attack the aryl isocyanide (2) to form the corresponding radical intermediate $\mathbf{I N}_{3}\left(\Delta G^{\ddagger}=6.6 \mathrm{kcal} / \mathrm{mol}\right)$. Subsequently, $\mathbf{I N}_{3}$ may undergo a single electron transfer (SET) pathway with lithium sulphide cation radicals to obtain intermediate cation IN4, followed by cyclization to form intermediate $\mathbf{I N}_{5}$ via the electrophilic attack on the aromatic ring. It is worthy noted that $\mathbf{I N}_{3}$ may also undergo radical cyclization first to obtain the cyclized radical intermediate $\mathbf{I N}_{5}$ ' and then obtain $\mathbf{I N}_{5}$ through the SET pathway with lithium sulphide cation radicals. Finally, deprotonation with $\mathrm{Nphth}^{-}$to deliver the alkylation product (3) is facile with an energy barrier of only $2.6 \mathrm{kcal} / \mathrm{mol}$. 


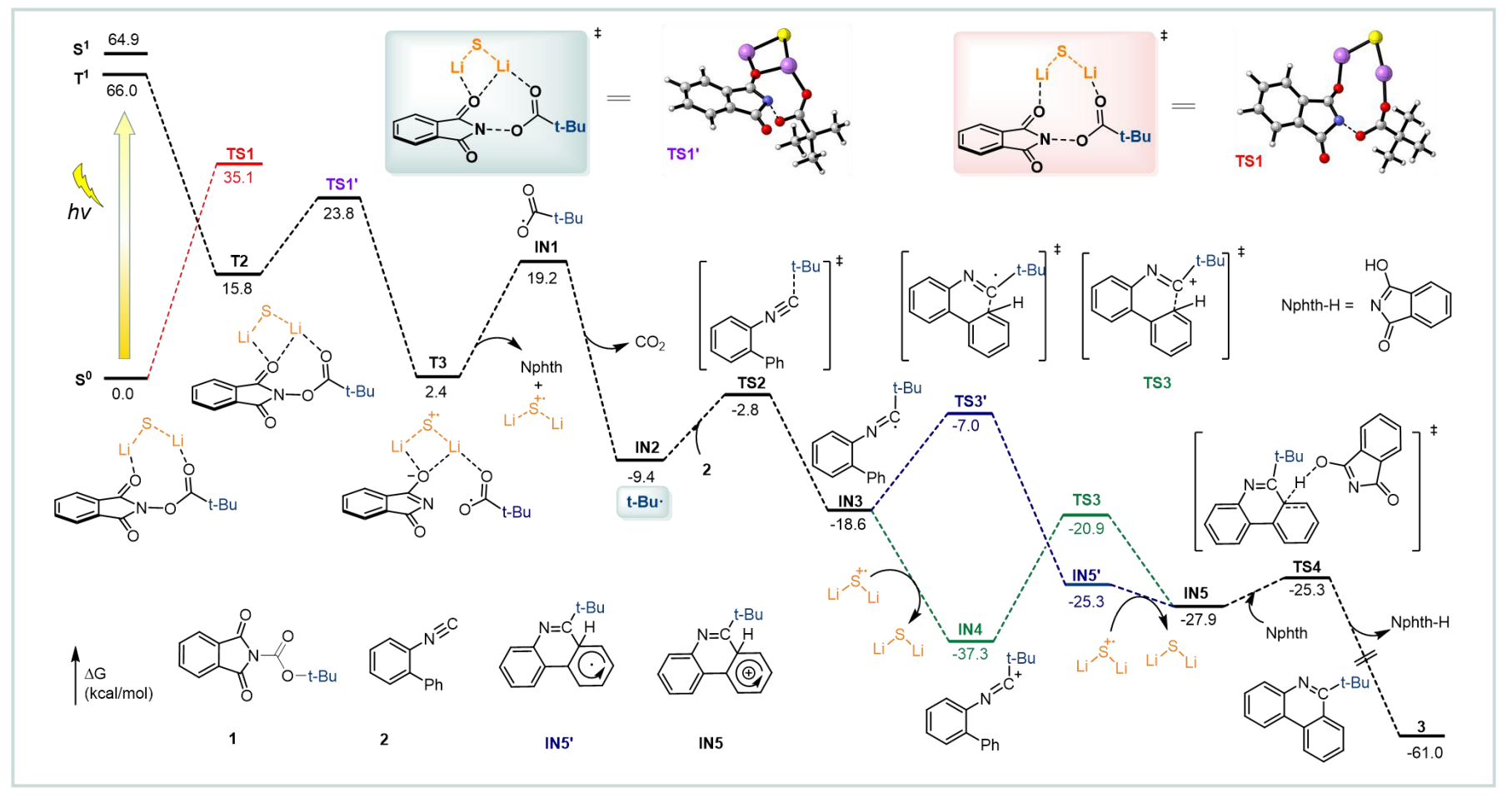

Scheme 4 | DFT calculations

\section{Conclusions}

In summary, we found that a charge-transfer complex spontaneously assembled with commercially available lithium sulphide and redox-active esters (RAEs) in amide solvents. An array of primary, secondary, tertiary and amino acid-derived RAEs were all amenable electron-acceptor substrates for undergoing radical decarboxylation and coupled with a diverse range of nucleophiles under $427 \mathrm{~nm}$ purple LED irradiation. Moreover, Katritzky's salt and Togni's reagent were also demonstrated to be suitable substrates, affording deaminative alkylation and trifluoromethylation products with high efficiency. This novel manifold featured a broad substrate scope and good functional group compatibility and was amenable to conducting the reaction in continuous-flow conditions, further enhancing its potential for application in large-scale synthesis. Mechanistic studies are consistent with the proposed reaction pathway in which CTC was activated with visible-light irradiation to undergo IEC, producing an alkyl radical and a sulphide anion radical intermediate. This new photoactivation concept presented in our work is anticipated to inspire future development of photocatalysis.

\section{Methods}

General procedure for decarboxylative alkylation of isocyanides. isocyanide ( $0.2 \mathrm{mmol}$, if it is solid), RAEs (150 mol \% - $200 \mathrm{~mol} \%), \mathrm{Li}_{2} \mathrm{~S}(20 \mathrm{~mol} \%)$ were placed in a $10 \mathrm{~mL}$ transparent Schlenk tube equipped with a stirring bar. The tube was evacuated and filled with argon (repeated for three times). To these solids, isocyanide ( $0.2 \mathrm{mmol}$, if it is liquid) and anhydrous DMA ( $1 \mathrm{~mL}$ ) were added 
using a gastight syringe under argon atmosphere. The reaction mixture was stirred under irradiation with purple LEDs $(427 \mathrm{~nm})$, maintained at approximately room temperature $\left(30 \pm 2{ }^{\circ} \mathrm{C}\right)$ by a desk fan in the air-conditioned room of $25^{\circ} \mathrm{C}$ for $12 \mathrm{~h}$. The mixture was then quenched with saturated $\mathrm{NaCl}$ solution and extracted with ethyl acetate $(3 \times 10 \mathrm{~mL})$. The organic layers were combined and concentrated under reduced atmospheric pressure. The product was purified by flash column chromatography on silica gel using petroleum ether/ethyl acetate as eluent.

\section{Data availability}

The authors declare that the data supporting the findings of this study are available within the article and Supplementary Information files, or from the corresponding author upon reasonable request. The experimental procedures, computational results, and characterization of all new compounds are provided in the Supplementary Information.

\section{Acknowledgements}

The authors acknowledge the support from the National Natural Science Foundation of China (21901237), China Postdoctoral Science Foundation (2018M640588) and Anhui Provincial Natural Science Foundation (1908085QB53)

\section{Author contributions}

M.-T.L. and D-G.L. contributed equally to this work. G-Z.W. conceived the idea, directed the project and wrote the manuscript. D-G.L. performed the DFT calculations. M.-T.L. and Z.-W.Q. performed the experiments and analyzed the data. All the authors participated in the preparation of the manuscript.

\section{Competing interests}

The authors declare no competing interests.

\section{References}

Ilardi, E. A., Vitaku, E. \& Njardarson, J. T. Data-Mining for Sulfur and Fluorine: An Evaluation of Pharmaceuticals To Reveal Opportunities for Drug Design and Discovery. J. Med. Chem. 2014, 57, 2832 - 2842. Polymers, and Properties Chem. Rev. 2015, 115, 3036 - 3140. 
2005, 434, $470-477$.

Pauling, L. The Nature of the Chemical Bond and the Structure of Molecules and Crystals: An Introduction to Modern Structural Chemistry, Cornell University Press, 1960.

Pauling, L. The Nature of the Chemical Bond. IV. The Energy of the Single Bonds and the Relative Electronegativity of Atoms. J. Am. Chem. Soc. 1932, 54, 3570 - 3582.

Li, H.-Y., Tang, X.-X., Pang, J.- H., Wu, X.-Y., Yeow, E. K. L., Wu, J. \& Chiba, S. Polysulfide Anions as Visible Light Photoredox Catalysts for Aryl Cross-Couplings. J. Am. Chem. Soc. 2021, 143, $481-487$.

Wang, Y.-H., Li, Y.-M. \& Jiang, X.-F. Sulfur-Center-Involved Photocatalyzed Reactions. Chem. Asian J. 2018, 13, 2208 - 2242.

Dondi, D., Protti, S., Albini, A., Carpio, S. M. \& Fagnoni, M. Synthesis of $\gamma$-lactols, $\gamma$-lactones and 1,4-monoprotected Succinaldehydes under Moderately Concentrated Sunlight. Green Chem. 2009, 11, 1653-1659.

Pitre, S., McTiernan, P. C. D., Ismaili, H. \& Scaiano, J. C. Mechanistic Insights and Kinetic Analysis for the Oxidative Hydroxylation of Arylboronic Acids by Visible Light Photoredox Catalysis: A Metal-Free Alternative. J. Am. Chem. Soc. 2013, 135, 13286 - 13289.

McTiernan, C. D., Pitre, S. P. \& Scaiano, J. C. Photocatalytic Dehalogenation of Vicinal Dibromo Compounds Utilizing Sexithiophene and Visible-Light Irradiation. ACS Catal. 2014, 4, 4034 - 4039.

Wang, H. \& Jui, N. T. Catalytic Defluoroalkylation of Trifluoromethylaromatics with Unactivated AlkenesJ. Am. Chem. Soc. 2018, 140, $163-166$.

Mori, T. \& Inoue,Y. Charge-Transfer Excitation: Unconventional Yet Practical Means for Controlling Stereoselectivity in Asymmetric Photoreactions. Chem. Soc. Rev., 2013, 42, 8122 - 8133.

Hubig, S. M., Bockman, T. M. \& Kochi, J.K. Optimized Electron Transfer in Charge-Transfer Ion Pairs. Pronounced Inner-Sphere Behavior of Olefin Donors. J. Am. Chem. Soc., 1996, 118, 3842 - 3851.

Alkorta, I., Rozas, I. \& Elguero, J. Interaction of Anions with Perfluoro Aromatic Compounds. J. Am. Chem. Soc., 2002, 124, 8593-8598.

QuiÊtonero, D., Garau, C., Rotger, C., Frontera, A., Ballester, P., Costa, A. \& Dey, P. M. Angew. Chem. Int. Ed. 2002, 41, 3389 - 3392.

Kepler, S.; Zeller, M., \& Rosokha, S. V. Anion- $\pi$ Complexes of Halides with p- Benzoquinones: Structures, Thermodynamics, and Criteria of Charge Transfer to Electron Transfer Transition. J. Am. Chem. Soc. 2019, 141, $9338-9348$.

Rosokha, S. V. \& Kochi, J. K. Fresh Look at Electron-Transfer Mechanisms via the Donor/Acceptor Bindings in the Critical Encounter Complex. Acc. Chem. Res., 2008, 41, 641 - 653.

Schottel, B. L., Chifotides, H. T. \& Dunbar, K. R. Anion- $\pi$ interactions. Chem. Soc. Rev., 2008, 37, 68 83.

Fu, M.-C., Shang, R., Zhao, B., Wang, B. \& Fu, Y. Photocatalytic decarboxylative alkylations mediated by triphenylphosphine and sodium iodide. Science, 2019, 363, 1429 - 1434.

Prier, C. K., Rankic, D. A., MacMillan, D. W. C. Visible Light Photoredox Catalysis with Transition Metal Complexes: Applications in Organic Synthesis. Chem. Rev., 2013, 113, 5322 - 5363.

Romero, N. A. \& Nicewicz, D. A. Organic Photoredox Catalysis. Chem. Rev., 2016, 116, 10075 - 10166.

Skubi, K. L., Blum, T. R. \& Yoon, T. P. Dual Catalysis Strategies in Photochemical Synthesis. Chem. Rev., 2016, 116, 10035-10074.

Kochi, J. K., Carlson, R., Ragnarsson, U., Ericsson, T., Yamada, H., Långström, B. \& Tokii, T. Chemical Activation by Electron Transfer in Charge-Transfer Complexes. Formation and Reactions of Transient Ion Radical Pairs. Acta. Chem. Scand., 1990, 44, 409- 432.

Wang, G.-Z., Shang, R., Cheng, W.-M. \& Fu, Y. Irradiation-Induced Heck Reaction of Unactivated Alkyl Halides at Room Temperature. J. Am. Chem. Soc., 2017, 139, 18307-18312.

Wang, G.-Z., Shang, R. \& Fu, Y. Irradiation-Induced Palladium-Catalyzed Decarboxylative Heck Reaction of Aliphatic N-(Acyloxy)phthalimides at Room Temperature. Org. Lett., 2018, 20, 888 - 891. Wang, G.-Z., Liu, D.-G., Liu, M.-T. \& Fu, Y. Photocatalyst- and Additive-free Site-specific C( $\left.\mathrm{sp}^{3}\right)-\mathrm{H}$ Hydrazination of Glycine Derivatives and Peptides. Green Chem., 2021, 23, 5082 - 5087. 
Jin, Y.-H., Jiang, M., Wang, H. \& Hua Fu. Installing Amino Acids and Peptides on N-heterocycles Under Visiblelight Assistance. Sci. Rep. 2016, 6, 20068

Xie, J., Xu, P., Li, H., Xue, Q., Jin, H., Cheng, Y. \& Zhu, C. A Room Temperature Decarboxylation/C-H Functionalization Cascade by Visible-Light Photoredox Catalysis. Chem. Commun., 2013, 49, 5672 5674.

Beato, E. de P.; Spinnato, D., Zhou, W. \& Melchiorre, P. A General Organocatalytic System for Electron Donor-Acceptor Complex Photoactivation and Its Use in Radical Processes. 2021, doi.org/10.1021/jacs.1c05607.

Jiang, H., Cheng, Y., Wang, R., Zheng, M., Zhang, Y. \& Yu, S. Synthesis of 6-alkylated Phenanthridine Derivatives Using Photoredox Neutral Somophilic Isocyanide Insertion. Angew. Chem., Int. Ed. 2013, 52, $13289-13292$.

31 Wang, Y.-T., Fu, M.-C., Zhao, B., Shang, R. \& Fu, Y. Photocatalytic Decarboxylative Alkenylation of $\alpha$-amino and $\alpha$-hydroxy Acid-Derived Redox Active Esters by NaI/PPh3 Catalysis. Chem. Commun., 2020, 56, $2495-2498$.

Wang, G.-Z., Fu, M.-C., Zhao, B. \& Shang, R. Photocatalytic Decarboxylative Alkylations of C(sp3) - H and $\mathrm{C}\left(\mathrm{sp}^{2}\right)-\mathrm{H}$ Bonds Enabled by Ammonium Iodide in Amide Solvent. Sci. China Chem., 2021, 64, 439 -444 .

Wu, J., He, L., Noble, A. \& Aggarwal, V. K. Photoinduced Deaminative Borylation of Alkylamines. J. Am. Chem. Soc., 2018, 140, $10700-10704$.

Zhang, B, Muck-Lichtenfeld, C., Daniliuc, C. G. \& Studer, A. 6-Trifluoromethyl-Phenanthridines through Radical Trifluoromethylation of Isonitriles. Angew. Chem. Int. Ed., 2013, 52, 10792 - 10795.

Cheng, W.-M., Shang, R., Zhao, B., Xing, W.-L., \& Fu, Y. Isonicotinate Ester Catalyzed Decarboxylative Borylation of (Hetero)Aryl and Alkenyl Carboxylic Acids through N-Hydroxyphthalimide Esters. Org. Lett. 2017, 19, 4291 - 4294.

Plutschack, M. B., Pieber, B., Gilmore K. \& Seeberger, P. H. The Hitchhiker's Guide to Flow Chemistry. Chem. Rev., 2017, 117, 11796 - 11893.

Cambie, D., Bottecchia, C., Straathof, N. J. W., Hessel, V. \& Noel, T. Applications of Continuous-Flow Photochemistry in Organic Synthesis, Material Science, and Water Treatment. Chem. Rev., 2016, 116, 10276 - 10341.

All calculations were performed with the Gaussian 16 program. The DFT functional of $\omega$ B97XD /def2TZVP was used for geometry optimization, frequency analysis and single-point energy calculations of all intermediates and transition states. The solvent effects were taken into account in all calculations by employing the SMD (N, N-DiMethylAcetamide) solvation model. Further details are given in the ESI.

\section{TOC}

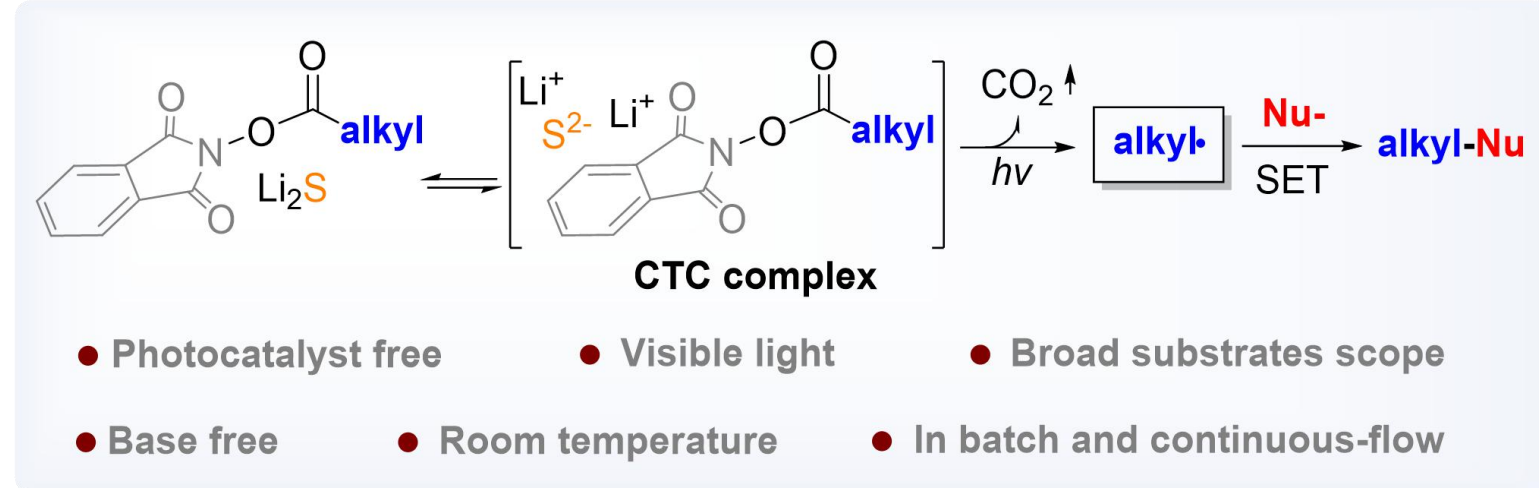

